\title{
REMARKS ON A PAPER BY SILVERMAN
}

\author{
VIKRAMADITYA SINGH
}

(Received 15 August 2000 and in revised form 23 November 2000)

ABSTRACT. We improve a result in Silverman's paper (1999) and answer a question he posed. We also consider a similar problem and obtain sufficient conditions for starlikeness.

2000 Mathematics Subject Classification. 30C45.

1. Introduction. Let $A$ be the class of analytic functions in the unit disc $U=\{z$ : $|z|<1\}$ having expansion of the form

$$
f(z)=z+a_{2} z^{2}+a_{3} z^{3}+\cdots
$$

and let $S \subset A$ be the set of univalent functions in $U$. A function $f \in S$ is said to be starlike of order $\alpha, 0<\alpha<1$, and is denoted by $S_{\alpha}^{*}$ if $\operatorname{Re} z\left(f^{\prime}(z) / f(z)\right)>\alpha, z \in U$ and is said to be convex and is denoted by $C$ if $\operatorname{Re}\left\{1+z\left(f^{\prime \prime}(z) / f^{\prime}(z)\right)\right\}>0, z \in U$. Silverman [2] investigated properties of the functions $f \in A$ and the class

$$
G_{b}=\left\{f \in A||\left(\frac{1+z\left(f^{\prime \prime}(z) / f^{\prime}(z)\right)}{z\left(f^{\prime}(z) / f(z)\right)}\right)-1 \mid<b, z \in U\right\} .
$$

Some of the results established by him and relevant to us are given in the following theorem.

THEOREM 1.1. Let $f \in G_{b}$ then

(i) If $0<b \leq 1, G_{b} \subset S^{*}(2 /(1+\sqrt{1+8 b}))$ and in particular $G_{1} \subset S^{*}(1 / 2)$.

(ii) $G_{b} \subset C$ for $0<b \leq 1 / \sqrt{2}$ and $G_{1} \not \subset C$.

(iii) For $b \geq 11.66, G_{b} \not \subset S^{*}(0)$ and for large enough $b, G_{b} \not \subset S$.

His method did not extend to $b>1$ and he expected the order of starlikeness of $G_{b}$ to decrease from $1 / 2$ to 0 as $b$ increases from 1 to some value $b_{0}$ after which functions in $G_{b}$ need not be starlike.

In this paper we establish the following theorems.

THEOREM 1.2. Let $f \in G_{b}, 0<b \leq 1$, then $G_{b} \subset S^{*}(1 /(1+b))$ and this order of starlikeness is sharp. Furthermore, for $b>1$ the elements of $G_{b}$ need not be regular in $U$.

We notice that if we put $p(z)=z\left(f^{\prime}(z) / f(z)\right)$, then $p(z)$ is analytic in $U$ with $p(0)=1$ and $G_{b}$ gets transformed to

$$
G_{b}=\left\{f \in A, p(z)=z \frac{f^{\prime}(z)}{f(z)}|| z \frac{p^{\prime}(z)}{p^{2}(z)} \mid<b, z \in U\right\} .
$$


DEFINITION 1.3. An analytic function $f(z)$ is said to be subordinate to another analytic function $g(z)$, denoted symbolically as $f(z) \prec g(z)$, if $f(0)=g(0)$ and there exists an analytic function $\omega(z) \in A, \omega(0)=0$ and $|\omega(z)|<1, z \in U$ such that $f(z)=g(\omega(z))$.

THEOREM 1.4. Let $-1 \leq \alpha \leq 1,0 \leq a<1, \lambda>0$ and let $p(z)$ be an analytic function in $U, p(0)=1, p(z) \neq 0, z \in U$ satisfy the subordination

$$
z \frac{p^{\prime}(z)}{p^{2}(z)} \prec \frac{\lambda z}{(1+a z)^{1+\alpha}} .
$$

Then

$$
\begin{gathered}
\frac{1}{p(z)} \prec 1-\frac{\lambda}{a \alpha}\left(1-(1+a z)^{-\alpha}\right), \quad \alpha \neq 0, \\
\operatorname{Re} \frac{1}{p(z)}>0 \quad \text { if } 0<\lambda \leq \frac{a \alpha}{1-(1+a)^{-\alpha}}, \quad \alpha \neq 0 .
\end{gathered}
$$

For $\alpha=0$ and $0<\lambda \leq a / \log (1+a)$

$$
p(z) \prec \frac{1}{1-(\lambda / a) \log (1+a z)}, \quad \operatorname{Re} p(z)>\left(1-\frac{\lambda}{a} \log (1-a)\right)^{-1} .
$$

The special case of (1.4) for $\alpha=1, \lambda=b-a,-1 \leq b<a \leq 1$ had been considered in [1]. Silverman's case corresponds to $\alpha=-1$.

In the notation of subordination the class $G_{b}$ defined by (1.3) can equivalently be written as

$$
G_{b}=\left\{f \in A, p(z)=z \frac{f^{\prime}(z)}{f(z)} \mid z \frac{p^{\prime}(z)}{p^{2}(z)} \prec b z, z \in U\right\} .
$$

We need the following result from [3].

THEOREM 1.5. If $h$ is starlike in $U, h(0)=0$ and $p$ is analytic in $U, p(0)=1$ satisfies

$$
z p^{\prime}(z) \prec h(z)
$$

then

$$
p(z) \prec q(z)=1+\int_{0}^{z} \frac{h(t)}{t} d t,
$$

where $q$ is a convex function.

2. Proof of Theorem 1.2. From (1.7), $f \in G_{b}$ is equivalent to

$$
z \frac{p^{\prime}(z)}{p^{2}(z)}=b \omega(z), \quad \omega(0)=0,|\omega(z)|<1 .
$$

By integration from 0 to $z$ and using $p(0)=1$, we get

$$
\frac{1}{p(z)}=1-b \int_{0}^{1} \frac{\omega(t z)}{t} d t .
$$


From (2.2) using Schwartz lemma for $\omega(z)$, we get

$$
\left|1-\frac{1}{p(z)}\right| \leq b|z|
$$

or equivalently, $|z|=r$ and

$$
\left|p^{2}(z)\right|-2 \operatorname{Re} p(z)+1 \leq b^{2} r^{2}\left|p^{2}(z)\right|
$$

Therefore, if $b \leq 1$,

$$
\left(1-b^{2} r^{2}\right)\left|p^{2}(z)\right|-2 \operatorname{Re} p(z)+1 \leq 0 .
$$

This is equivalent to

$$
\begin{gathered}
\left|p(z)-\frac{1}{1-b^{2} r^{2}}\right| \leq \frac{b r}{1-b^{2} r^{2}}, \quad \text { if } 0 \leq b \leq 1 \\
\left|p(z)+\frac{1}{b^{2}-1}\right| \geq \frac{b}{b^{2}-1}, \quad \text { if } b>1
\end{gathered}
$$

Equation (2.6) gives

$$
\operatorname{Re} p(z) \geq \frac{1}{1+b}
$$

and this is sharp because

$$
p(z)=\frac{1}{1+b z} \Rightarrow f(z)=\frac{z}{1+b z}
$$

satisfies (2.6). The function $p(z)$ given by (2.9) satisfies (1.7) even for $b>1$. However, (2.9) shows that for $b>1$ both $p(z)$ and $f(z)$ have a pole at $z=-1 / b$ and $\operatorname{Re} p(z)$ can be negative. Thus, the functions $f \in G_{b}$ for $b>1$ need not even be regular.

3. Proof of Theorem 1.4. We notice that the function $z /(1+a z)^{1+\alpha}, 0 \leq a<1$, is starlike for $0<\alpha \leq 1$ and convex for $-1 \leq \alpha \leq 0$. Since every convex function is starlike, we obtain, from (1.4) and Theorem 1.5,

$$
\begin{aligned}
& \frac{1}{p(z)} \prec 1-\frac{\lambda}{a \alpha}\left(1-(1+a z)^{-\alpha}\right), \quad \alpha \neq 0, \\
& \frac{1}{p(z)} \prec 1-\frac{\lambda}{a} \log (1+a z), \quad \alpha=0 .
\end{aligned}
$$

As $(1+a z)^{-\alpha},|\alpha| \leq 1, \alpha \neq 0$, is a convex function with real coefficients, we obtain

$$
\begin{aligned}
& \operatorname{Re} \frac{1}{p(z)}>0 \quad \text { if } 0<\lambda \leq \frac{a \alpha}{1-(1+a)^{-\alpha}},|\alpha| \leq 1, \alpha \neq 0, \\
& \operatorname{Re} \frac{1}{p(z)}>0 \quad \text { if } 0<\lambda \leq \frac{a}{\log (1+a)}, \alpha=0 .
\end{aligned}
$$


Hence,

$$
\operatorname{Re} p(z) \geq \frac{1}{1-(\lambda / a \alpha)\left\{1-(1-a)^{-\alpha}\right\}}, \quad \alpha \neq 0
$$

and $f(z)$ satisfying $p(z)=z\left(f^{\prime}(z) / f(z)\right)$ is starlike of order $1 /\left(1-(\lambda / a \alpha)\left\{1-(1-a)^{-\alpha}\right\}\right)$, $\alpha \neq 0$ and $1 /(1-(\lambda / a) \log (1-a))$ for $\alpha=0$.

In the special case $\alpha=1$ and $\lambda=a-b$ we obtain $\operatorname{Re} p(z) \geq(1-a) /(1-b),-1 \leq b<$ $a \leq 1$ which corresponds to the case in [1]. If $\alpha=-1$, we obtain $\operatorname{Re} p(z)>1 /(1+\lambda)$ which agrees with Theorem 1.2.

\section{REFERENCES}

[1] M. Obradović and S. Owa, A criterion for starlikeness, Math. Nachr. 140 (1989), 97-102. MR 90i:30020. Zbl 676.30009.

[2] H. Silverman, Convex and starlike criteria, Int. J. Math. Math. Sci. 22 (1999), no. 1, 75-79. MR 2000a:30028. Zbl 921.30009.

[3] T. J. Suffridge, Some remarks on convex maps of the unit disk, Duke Math. J. 37 (1970), 775-777. MR 42\#4722. Zbl 206.36202.

VIKRAMADITYA SINGH: 3A/95 AZAD NAGAR, KANPUR UP 208002, INDIA

E-mail address: rasingh@arocketmai 1. com 


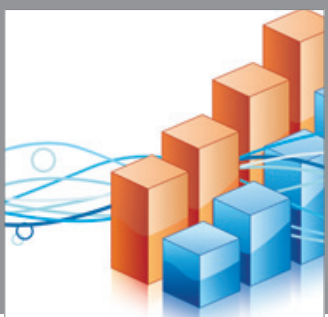

Advances in

Operations Research

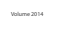

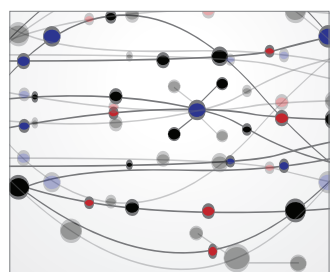

\section{The Scientific} World Journal
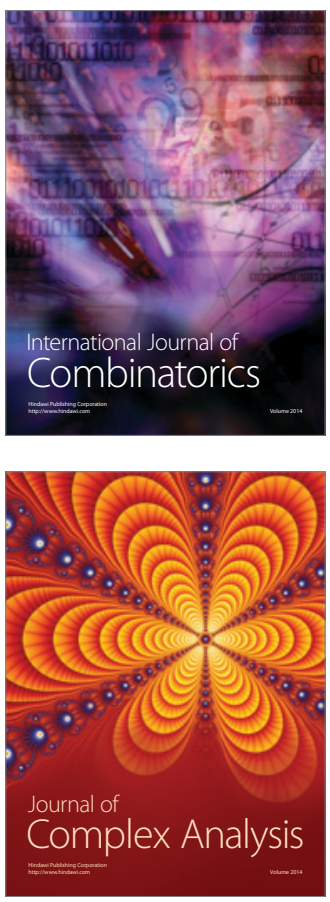

International Journal of

Mathematics and

Mathematical

Sciences
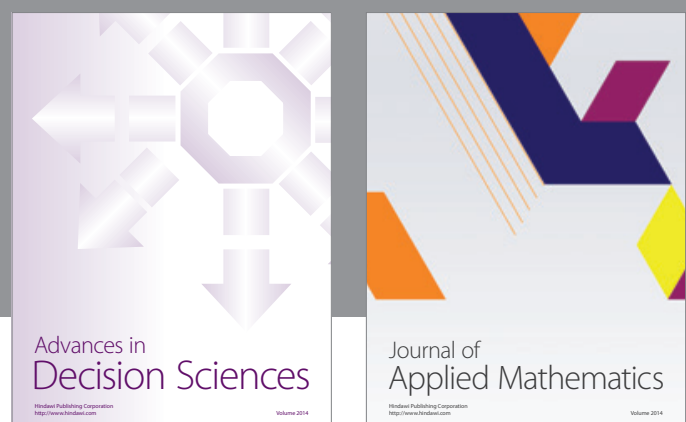

Journal of

Applied Mathematics
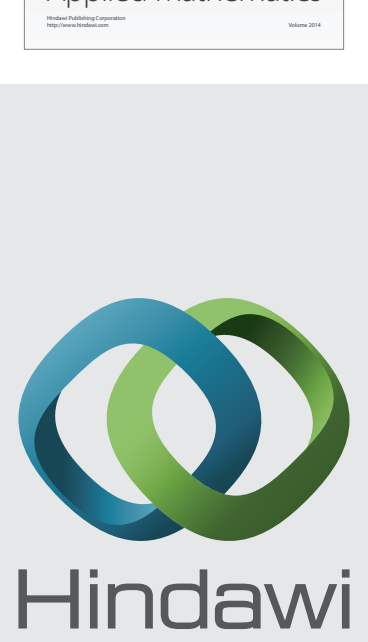

Submit your manuscripts at http://www.hindawi.com
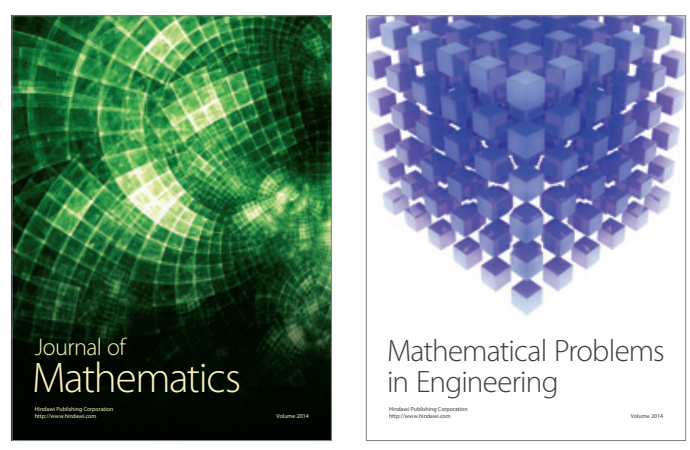

Mathematical Problems in Engineering
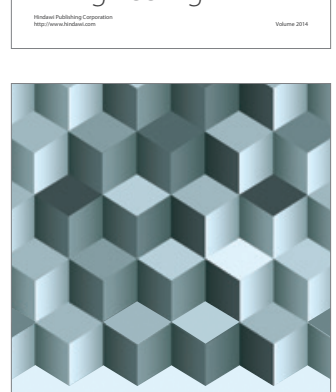

Journal of

Function Spaces
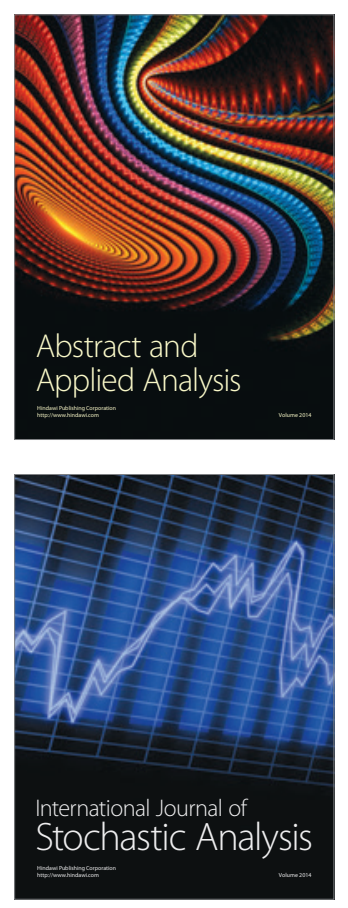

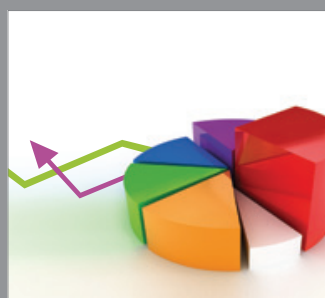

ournal of

Probability and Statistics

Promensencen
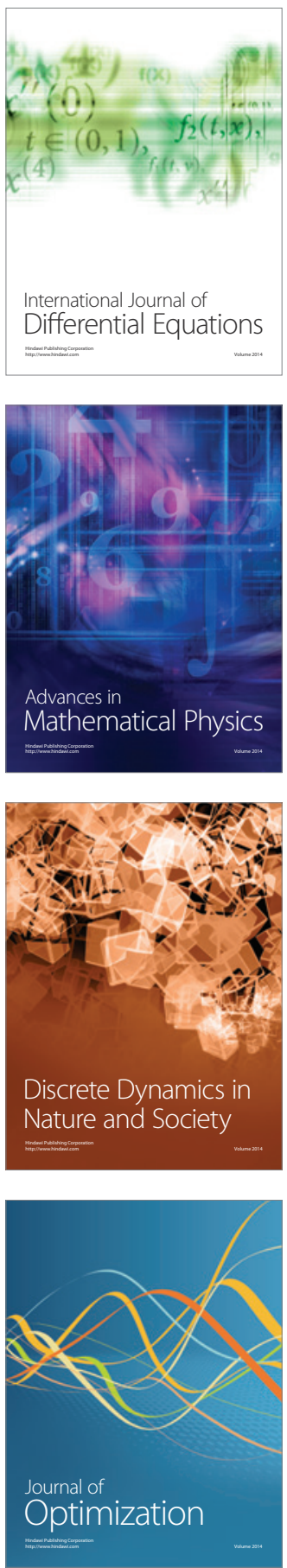